\title{
Development of time controlled chronomodulated tablet with swelling and rupturable layers: Optimization of factors influencing lag-time and drug release
}

\author{
Mayur Desai, Rishad R Jivani, Laxman D Patel, Noordin P Jivani, Bhavin Sonagara \\ Department of pharmaceutics, C. U. Shah College of Pharmacy \& Research, Wadwan, Gujarat, India
}

\begin{abstract}
Introduction: A tablet system consisting of cores coated with two layers of swelling and rupturable coatings was prepared and evaluated as time controlled chronomodulated tablet. Materials and Methods: Cores containing Montelukast sodium as model drug were prepared by direct compression and then coated sequentially with an inner swelling layer containing a HPMC E 5 and an outer rupturable layer of Eudragit RL/RS (1:1). A three-factor, two-level, full factorial design was used to investigate the influence of amount of HPMC E 5 and Eudragit RL/RS (1:1) on the responses, i.e., lag time to release and time required for $80 \%$ of drug to releases. The dissolution tests were studied using the USP paddle method at $50 \mathrm{rpm}$ in $0.1 \mathrm{~N} \mathrm{HCL}$ for $2 \mathrm{hr}$ and than in phosphate buffer $\mathrm{pH}$ 6.8. Result: The lag time of the drug release decreased by increasing the inner swelling layer and increased by increasing the rupturing layer level. Conclusion: The results obtain from present study suggest that swelling come reputable coating approach gives desire drug release after lag time.
\end{abstract}

Key words: Asthma, cronomodulated drug delivery, Montelukast sodium, swelling layer

\section{INTRODUCTION}

In recent years, oral drug delivery systems with zero order sustained-release kinetics have been developed to control drug release using various mechanisms, including matrices with controllable swelling, diffusion, erosion, and osmotically driven systems. ${ }^{[1]}$

Nocturnal asthma, a condition prevalent in two-thirds of the asthmatics, is defined as a variable night time exacerbation of the underlying asthma condition associated with increase in symptoms and need for medication, increased airway responsiveness, and worsening of lung function. Symptoms typically occur between midnight and 8.00 am, especially around $4.00 \mathrm{am} \cdot{ }^{[2-4]} \mathrm{It}$ is inconvenient to take the medication at

\section{Address for correspondence:}

Dr. Rishad Jivani,

Department of Pharmaceutics, C. U. Shah College of Pharmacy and Research, Opp. IBP Petrol Pump, Ahmadabad-Surandranagar Highway, Wadhwan City, Surandranagar - 363 030, Gujarat, India. Email: hellorishad@yahoo.com

\begin{tabular}{|l|l|}
\hline \multicolumn{2}{|c|}{ Access this article online } \\
\hline Quick Response Code: & Website: \\
\hline & www.jpionline.org \\
\cline { 2 - 2 } & DOI: \\
\hline
\end{tabular}

midnight. The maintenance of constant drug level is not always desirable for the optimal therapy. A drug should be delivered only when and/or where it is needed at the minimum required dose. ${ }^{[5]}$ For the drugs to follow circadian rhythm, like in asthma, a reasonable and an acceptable rationale is a delivery system capable of releasing drugs in a pulsatile fashion rather than as a continuous delivery at the predetermined time/site following oral administration. ${ }^{[6,7]}$

This study attempts to design and evaluate a time controlled chronomodulated drug delivery system of Montelukast sodium (ML) for the treatment of nocturnal asthma. It was aimed to have a lag time of six hours i.e., the system is taken at the bed time and expected to release the drug after a period of six hr when the asthma attacks are more prevalent. Such time-controlled cronomodulated delivery can be achieved mainly with drug containing cores, which are covered with release controlling layers. The core serves as reservoir, and the release controlling layers protect the core from the environment e.g., water, acidic $\mathrm{pH}$, and enzymes until the drug is released after a predetermined lag phase. The coatings can erode/dissolve, rupture or alter their permeability at the required time. Single unit rupturable pulsatile drug delivery system was chosen as the model system over erodible pulsatile drug delivery system or Pulsincap ${ }^{\circledR}$ and PORT ${ }^{\circledR}$ systems ${ }^{[8]}$ because of ease of manufacturing, better reproducibility of the lag time, and rapid drug release after a lag time. The projected system consisted of core tablet coated with an inner swelling layer (HPMC E5) and an outer rupturable coating (Eudragit RL/RS) aimed to release the drug after a lag time of $6 \mathrm{hr}$. 


\section{MATERIALS AND METHODS}

\section{Materials}

Montelukast sodium was obtained as a gift sample from Cadila Healthcare Ltd., Ahmadabad, India. HPMC E5 provided as gift sample from Colorcon Asia Ltd., Goa, India. Eudragit RL/RS, MCC PH 102 and Crosprovidone were obtained as gift samples from Lincoln Pharma Pvt. Ltd., Ahmadabad, India. PEG 4000 was purchased from $\mathrm{CDH}$, Mumbai, India. All other chemicals used were of analytical reagent grade.

\section{Method of preparation of core tablet of montelukast sodium}

The core tablets containing Montelukast sodium (10 mg/tablet) were prepared by using Superdisintegrant like CrosProvidone, SSG, and Crosscarmellose sodium, diluents like microcrystalline cellulose (MCC PH102), magnesium stearate, and talc.

All excipients were mixed for $20 \mathrm{~min}$ and passed through a 40 mesh size sieve and directly compressed in to $200 \mathrm{mg}$ tablets using $9.6 \mathrm{~mm}$ round concave punches on a rotary tablet machine (Rimek, Ahmadabad, India). Tablet hardness was measured with Monsanto hardness tester and was found to be $3.0 \pm 0.5 \mathrm{~kg}$.

\section{Fabrication of time controlled cronomodulated tablet of montelukast sodium}

Cronomodulated tablets were prepared by coating core tablets with an inner swelling layer comprising of HPMC E5 and an outer polymeric layer consisting of Eudragit RL/RS (1:1) dispersed in water/ethanol (60/40 v/v) using PEG 4000 (5\% w/w of polymer content) as a plasticizer. Inner swelling layer was applied by direct compression whereas outer polymeric layer was incorporated by conventional pan coating. The process conditions used were as: Inlet temperature $40-45^{\circ}$; product temperature $33-35^{\circ}$; pan speed $30 \mathrm{rpm}$; spray rate $4-6 \mathrm{~g} / \mathrm{min}$; atomizing pressure 1.2 bar. The coated tablets were further dried in a coating pan for $15 \mathrm{~min}$ at $35^{\circ}$. After finishing the coating process the tablets were then placed in an oven at $50^{\circ}$ for $2 \mathrm{~h}$ to remove the solvent. The surface morphology of the tablet was smooth and uniform in appearance.

\section{In vitro drug release studies}

The in vitro drug release from coated tablets was carried out using USP paddle apparatus at $50 \mathrm{rpm}$ and $37 \pm 0.5^{\circ} \mathrm{HCl}(0.1 \mathrm{~N})$ and phosphate buffer ( $\mathrm{pH}$ 6.8) were used as the dissolution medium. Initially tablets were subjected to dissolution in $0.1 \mathrm{~N} \mathrm{HCl}$ for $2 \mathrm{~h}$ and after that media were changed to phosphate buffer ( $\mathrm{pH}$ 6.8). The samples were withdrawn at regular intervals and analyzed by UV spectrophotometer ${ }^{[9]}$ (Shimadzu UV/Vis 1601) at $276 \mathrm{~nm}$ for the presence of the drug. Dissolution tests were performed in triplicate.

\section{Full factorial design}

Two factors each at three levels were selected and experimental trials were performed at all possible nine combinations. In the present investigation, the percentages of HPMC E 5 (X1) and
Eudragit RL/RS (1:1) (X2) were chosen as the independent variables. Lag time and time required for $80 \%$ of drug release $\mathrm{t}_{80 \%}$ were selected as the dependent variables. The experimental design with the corresponding formulations is outlined in Table 1. HPMC E 5 was used at $22 \%, 25 \%$, and $28 \%$, while Eudragit RL/RS (1:1) was used at $8 \%, 9 \%$, and $10 \%$. A statistical model incorporating interactive and polynomial terms was used to evaluate the responses: $\mathrm{Y}=\mathrm{b}_{0}+\mathrm{b} 1 \times 1+\mathrm{b} 2 \times 2+\mathrm{b} 12 \times 1$ $\times 2+\mathrm{b} 11 \times 12+\mathrm{b} 22 \times 22$, where $\mathrm{Y}$ is the dependent variable, $\mathrm{b}_{0}$ is the arithmetic mean response of the nine runs and any $b$ is the estimated coefficients for the related factor $\mathrm{Xi}$. The main effects (X1 and X2) represent the average result of changing one factor at a time from its low to high value. The interaction term "X1 $\times 2$ " shows how the response changes when the two factors change simultaneously. The polynomial terms (X12 and X22) are included to investigate nonlinearity.

\section{Statistical analysis}

The statistical analysis of the all factorial design batches were performed by multiple regression analysis using Sigma State Software (Sigma State 3.5. SPSS, USA). To demonstrate graphically the influence of each factor on responses, response surface plots were generated using STATISTICA 10 (Stat Soft Inc., Tulsa, OK, USA) Software. The $P<0.05$ was considered to be significant.

\section{Scanning electron micrograph}

The tablet was transversely cut and was sputtered with gold (30 $\mathrm{mm}$ thick) under vacuum and microscopy was performed with a LEO-435 VP, PC based digital scanning electron microscope. It was viewed for the presence of polymer layer at 600X magnification.

\section{RESULTS AND DISCUSSION}

To optimize core tablet, different superdisintegrant like SSG, Crospovidone, and Crosscarmellose sodium were used along with directly compressible diluents microcrystalline cellulose (MCC PH102). Here, MCC was used because of its excellent compression properties and high dilution potential. ${ }^{[10]}$

\begin{tabular}{|c|c|c|c|c|c|c|}
\hline \multirow[t]{2}{*}{ Batch code } & \multicolumn{2}{|c|}{$\begin{array}{c}\text { Real } \\
\text { values }\end{array}$} & \multicolumn{2}{|c|}{$\begin{array}{c}\text { Transformed } \\
\text { values }\end{array}$} & \multicolumn{2}{|c|}{ Dependent variable } \\
\hline & $\mathrm{X}_{1}$ & $\mathrm{X}_{2}$ & $X_{1}$ & $\mathrm{X}_{2}$ & Y1 (Min) & Y2 (Min) \\
\hline F1 & 22 & 8 & -1 & -1 & 335 & 357 \\
\hline F2 & 22 & 9 & -1 & 0 & 385 & 414 \\
\hline F3 & 22 & 10 & -1 & +1 & 400 & 444 \\
\hline $\mathrm{F} 4$ & 25 & 8 & 0 & -1 & 275 & 288 \\
\hline F5 & 25 & 9 & 0 & 0 & 360 & 384 \\
\hline F6 & 25 & 10 & 0 & +1 & 390 & 414 \\
\hline F7 & 28 & 8 & +1 & -1 & 160 & 222 \\
\hline F8 & 28 & 9 & +1 & 0 & 250 & 321 \\
\hline F9 & 28 & 10 & +1 & +1 & 305 & 351 \\
\hline
\end{tabular}

$X_{1}$ is the \% of HPMC $E_{1}, X_{2}$ is the \% of Eudragit RL/RS (1:1), $Y_{1}$ is lag time and $Y_{2}$ is time required for $80 \%$ of drug release. All batches contain $10 \mathrm{mg}$ of Montelukast sodium. Data are expressed as mean values and standard deviations (+ SD), $n=3$ 
Prepared core tablet comply pharmacopeia requirements in terms of hardness, friability, and weight variation. Among all superdisintegrants, Crosprovidone, showed disintegration time $12 \mathrm{sec}$ and released $95 \%$ drug in $15 \mathrm{~min}$. Observed effect could be due to porous particle morphology of Crospovidone, which enables them to rapidly absorb liquids into the tablet by capillary action and to generate rapid volume expansion and hydrostatic pressures that result in fast tablet disintegration. ${ }^{[1]}$

Visually, tablets formulated with CrosPovidone (4\%) could be seen to rapidly disintegrate into more or less uniform fine particles, while tablets formulated with Croscarmellose sodium and Sodium starch glycolate appeared to disintegrate much more slowly into more or less uniform coarser particles. Optimized core tablet formula showed in Table 2 which was used for further study.

Time controlled cronomodulated drug delivery system consisted of a core, a drug containing reservoir, inner or intermediate swelling layer, and an outer water insoluble but permeable coating. The swelling layer consisted of hydroxypropyl methyl cellulose (HPMC E5). It was chosen because of its swelling nature and its eroding behavior ${ }^{[12]}$ and was applied by direct compression method. The rupturable coating consisted of a plasticized mixture of Eudragit RL/RS (1:1), as it formed a mechanically weak and semi permeable film, which could rupture easily upon exposure to the dissolution media, and was water insoluble, swellable, and $\mathrm{pH}$ independent film former. ${ }^{[13]}$ As the numbers of hydrophilic quaternary ammonium groups present in Eudragit RL were much higher as compared to RS, faster drug release was observed from it. The drug release could be modified by adjusting the ratio of these two polymers in combination.

Figure 1 shows a transverse-sectioned photograph of time-dependent zt. The parts of the tablet as seen in the figure, the core (MCC, Crosprovidon, and drug), an intermediate swelling/ eroding layer comprising of HPMC E5, and homogenous rupturable layer consisting of Eudragit RL/RS mixture (1:1). Water influx was through the semi permeable rupturable outer coating, which leads to the expansion and erosion of an

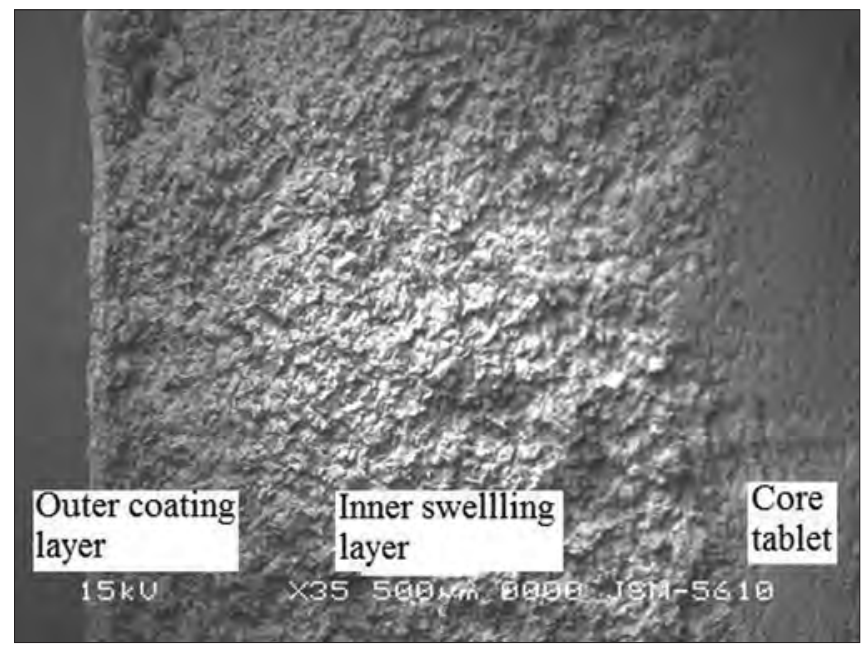

Figure 1: Scanning electron microscopy of optimized batch (MD1) intermediate layer that ultimately resulted in rupture of the outer coating. The drug was then released within a short time after a definite lag time period. The dissolution studies were carried out to investigate the release behavior of the developed system. Figure 2 shows dissolution studies of the time controlled cronomodulated tablet of ML containing varying concentrations of HPMC E 5 and Eudragit RL/RS (1:1).

It is desirable to develop an acceptable pharmaceutical formulation in shortest possible time using minimum number of man-hours and raw materials. Traditionally, pharmaceutical formulations are developed after changing one variable at a time approach. The method is time consuming in nature and requires a lot of imaginative efforts. Moreover, it may be difficult to develop an ideal formulation using this classical technique since the joint effects of independent variables are not considered. It is, therefore, very essential to understand the complexity of pharmaceutical formulations by using established statistical tools such as factorial design.

The two-factor, three-level full factorial design was applied in this study to optimize the time controlled cronomodulated tablet containing ML. From the preliminary trials, it was revealed that concentration of HPMC E5(\%) and Eudragit RL/RS (1:1) shows influence on characteristics and performance of cronomodulated tablet of ML. The observed responses for nine formulations are given in Table 1.

The mathematical relationship in the form of factor coefficients and their corresponding $P$ values for the measured responses are listed in Table 3. Coefficients with a $P$ value less than 0.05 had a

\begin{tabular}{lc}
$\begin{array}{l}\text { Table 2: Optimized formula for core tablet of } \\
\text { Montelukast sodium }\end{array}$ \\
\hline Ingredients & $\begin{array}{c}\text { Quantity for } \mathbf{1} \\
\text { Tablet (mg) }\end{array}$ \\
\hline Montelukast sodium & 10 \\
Crospovidone & 8 \\
MCC PH102 & 176 \\
Magnesium stearate & 4 \\
Talc & 2 \\
Total quantity & 200 \\
\hline
\end{tabular}

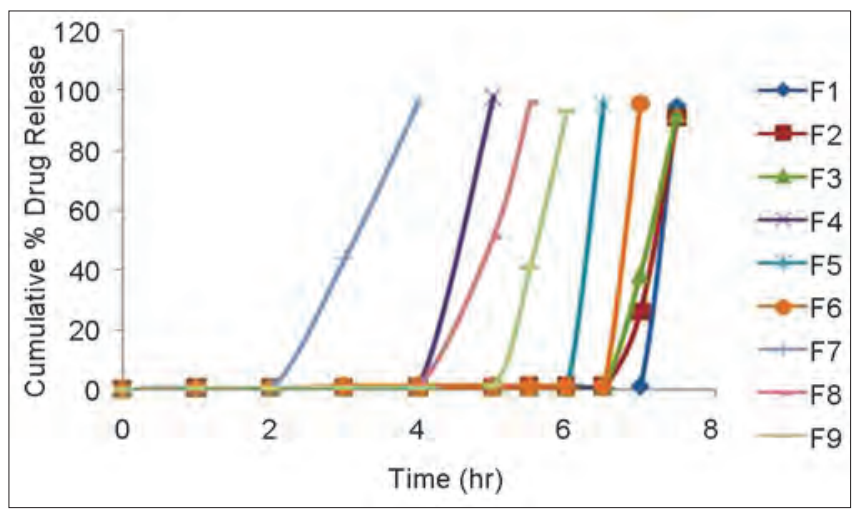

Figure 2: In vitro dissolution profile of time controlled cronomodulated tablet of Montelukast sodium 
Table 3: The Summary of regression analysis of measured responses

\begin{tabular}{lccccccc}
\hline Parameters & \multicolumn{7}{c}{ Co-efficient of regression parameters } \\
\cline { 2 - 7 } & $\mathbf{b}_{0}$ & $\mathbf{b}_{1}$ & $\mathbf{b}_{\mathbf{2}}$ & $\mathbf{b}_{\mathbf{1 2}}$ & $\mathbf{b}_{\mathbf{1 1}}$ & $\mathbf{b}_{\mathbf{2 2}}$ & $\mathbf{R}^{\mathbf{2}}$ \\
\hline Lag time & 355.556 & -67.5 & 54.167 & -20.833 & -35.833 & 20 \\
$P$ - Value & 0.00 & 0.001 & 0.006 & 0.055 & 0.177 & 0.682 & 0.998 \\
$\mathrm{t}_{80 \%}$ & 380 & -53.5 & 57 & -27 & -10.5 & -10.5 \\
$P$-Value & 0.00 & 0.003 & 0.060 & 0.048 & 0.012 & 0.589 & 0.993 \\
\hline
\end{tabular}

significant effect on the prediction efficiency of the model for the measured response. The values of the coefficients $X 1$ and $X 2$ are related to the effect of these variables on the responses $\mathrm{Y} 1$ and Y2. Coefficients with more than one factor term and those with higher-order terms represent interaction terms. Concerning the $P$ values of the coefficients, $X 1, X 2, X 1 \times 2, X 1^{2}$, and $X 2^{2}$ were found to have significant effects on the performance of the model for the prediction of the lag time and time required for $80 \%$ of drug release.

The relationship between the dependent and independent variables was further elucidated using contour plots. The effect of $X 1$ and $X 2$ and their interaction on responses $Y 1$ and $Y 2$ is given in Figures 3 and 4, respectively.

The multiple regression data obtained for response $Y 1$ (lag time) showed a higher coefficient value for factor $X 1$ than for factor $X 2$. This indicated the dominating effect of HPMC E 5 concentration on the response Y1. Thickness of the swelling layer was the critical parameter which influenced the rupture of outer coating. The lag time of tablet decreased with increasing level of swelling layer [Figure 3]. As the amount of swelling agent (HPMC E5) increased, it exerted more pressure over the outer layer resulting in rapid rupturing of the tablet. The expanded swelling layer facilitated the entry of dissolution medium to the core containing sueprdisintegrant, which further synergized the rupturing of the outer layer. After breaking of the outer layer, the drug is released from the time dependent release tablet.

A cronomodulated release profile is characterized by a lag time followed by rapid and complete drug release. After the desired lag time, the onset of release can be achieved by use of a superdisintegrant in the core tablet.

In the present study, the extent of ML release was mainly influenced by the composition of the rupturable coat. The multiple regression data obtained for response Y2 (time required for $80 \%$ drug release) showed a higher coefficient value for factor $X 2$ than for factor $X 1$. This indicated the dominating effect of Eudragit RL/RS (1:1) concentration on the response Y1. Also, from the contour plot and multiple regression analysis, it was revealed that an increase in concentration of Eudragit RL/RS (1:1) decreased drug release while increasing concentration of HPMC E 5 increase drug release [Figure 4]. The water uptake capacity and drug release before the rupture of tablet was dependent on outer acrylate polymer coating. The lag time increased with increased outer coating level. With higher coating level of Eudragit, a slower

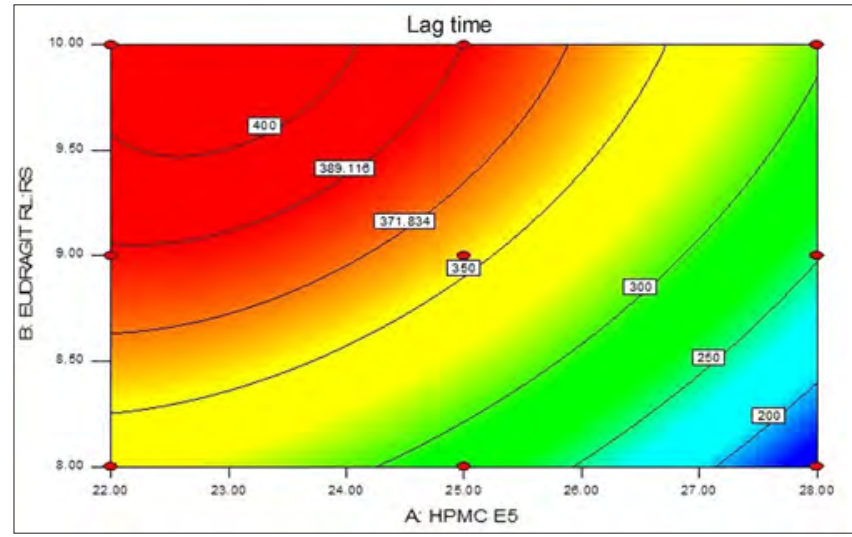

Figure 3: Contour plot showing lag time (min) using different combination of $X_{1}$ and $X_{2}$, the contour lines shows lag time ( $\mathrm{min}$ )

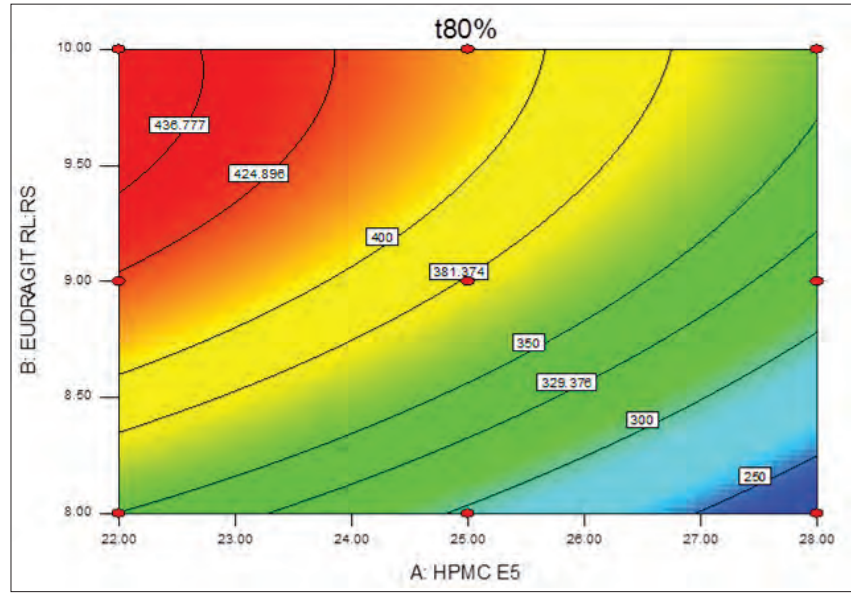

Figur 4: Contour plot showing $\mathrm{t} 80 \%$ ( $\mathrm{min}$ ) using different combination of $\mathrm{X}_{1}$ and $\mathrm{X}_{2}$ the contour lines shows time required for $80 \%$ drug release

release was observed after lag time, due to lower degree of rupturing. Increased outer coating level decreased the water uptake. This could be explained by the greater degree of mechanical strength of the thick coating.

From these observations, it can be assumed that the first step in drug release is penetration of water in the core tablet by diffusion through Eudragit film and the rate and amount of water entered is dependent on outer film thickness. The HPMC E5 layer was swelled when it came in contact with water. No remarkable increase in volume was observed before water reached the HPMC layer. The penetration rate of water accelerated due to polymer chain relaxation. When the water reached the core, due to presence of superdisinterating agents' presence in core drug gets released. 


\begin{tabular}{|c|c|c|c|c|}
\hline \multirow[t]{2}{*}{ Independent variables } & \multicolumn{2}{|c|}{ Predicted value } & \multicolumn{2}{|c|}{ Actual value } \\
\hline & $\begin{array}{l}\text { Lag time } \\
\text { (min) }\end{array}$ & $\begin{array}{c}t_{80 \%} \\
(\mathrm{~min})\end{array}$ & $\begin{array}{l}\text { Lag time } \\
\text { (min) }\end{array}$ & $\begin{array}{c}t_{80 \%} \\
(\mathrm{~min})\end{array}$ \\
\hline X1-HPMC E5=23.7 \% & 360.65 & 380.79 & 372.67 & 357.43 \\
\hline $\begin{array}{l}\text { X2-Eudragit } \\
\text { RL: RS }(1: 1)=8.67 \%\end{array}$ & & & & \\
\hline
\end{tabular}

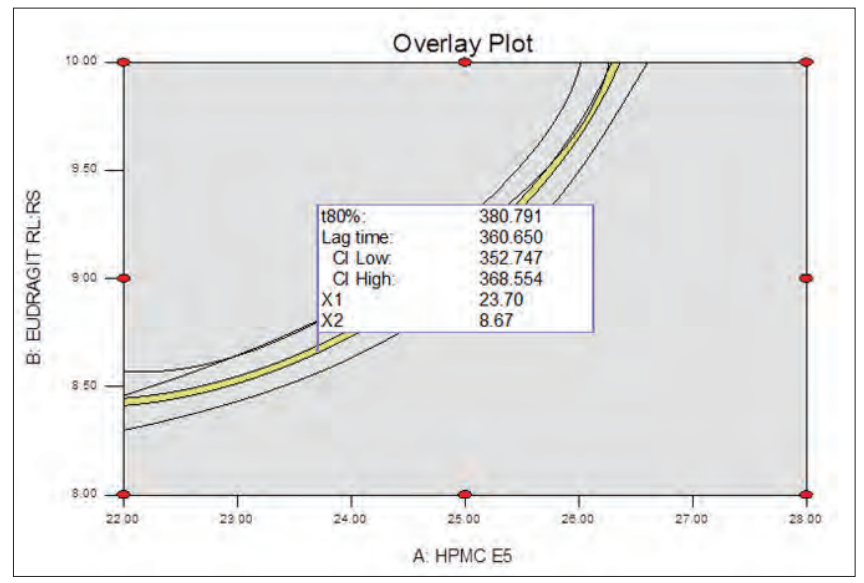

Figure 5: Overlapping contour plots of all variables

Figure 5 shows overlapping contour plot of all the dependent variables. Highlighted area suggests optimized area from these area check point batch were prepared. The Check point batch (MD1) containing $\mathrm{X}_{1}=23.7 \%$ and $\mathrm{X}_{2}=8.67 \%$ was formulated to get desirable lag time and release profile. The predicted and observed value for the lag time and $t_{80 \%}$ is depicted in Table 4.

Scanning electron micrograph revealed that the coated tablet had a fairly smooth and tight surface. It also revealed the presence of core, inner swelling layer and outer polymeric layer [Figure 1]. The coating layers were satisfactorily uniform.

\section{CONCLUSION}

A time controlled cronomodulate tablet of Montelukast sodium for the treatment of asthma was successfully developed. The system was found to be satisfactory in terms of release of the drug after a lag time of six hours. The dosage form can be taken at bed time and will release the contents in the early hours of morning when the asthmatic attacks are more prevalent. The release of the drug was sharp and complete after the lag time, which is necessary for any cronomodulated drug delivery system.

\section{ACKNOWLEDGMENTS}

Authors appreciated supports of Colorcon Asia Ltd., Goa (India) for providing gift sample of HPMC E 5. Authors also thanks Cadila Healthcare Ltd., Ahmadabad, for Montelukast sodium gift sample.

\section{REFERENCES}

1. Anal AK. Time-controlled pulsatile delivery systems for bioactive compounds. Recent Pat Drug Deliv Formul 2007;1:73-9.

2. Martin RJ, Banks-Schlegel S. Chronobiology of asthma. Am J Respir Crit Care Med 1998;158:1002-7.

3. Stroms WW, Bodman SF, Nathan RA, Byer P. Nocturnal asthma symptoms may be more prevalent than we think. J Asthma 1994;31:313-8.

4. Pincus DJ, Beam WR, Martin RJ. Chronobiology and chronotherapy of asthma. Clin Chest Med 1995;6:699-713.

5. D'Emanuele A. Responsive polymeric drug delivery systems. Meeting the patient's needs. Clin Pharmacokinet 1996;31:241-5.

6. Yoshida R, Sakai K, Okano T, Sakurai Y. Pulsatile drug delivery system using hydrogels. Adv Drug Deliv Rev 1993;11:85-108.

7. Lin SY, Lin YY, Chen KS. Permeation behavior of salbutamol sulphate through hydrophilic and hydrophobic membranes embedded by thermo-responsive cholestryl oleyl carbonate. Pharm Res 1996;13:914-9.

8. Crison JR, Siersma PR, Taylor MD, Amidon GL. Programmable oral release technology PORT system: A novel dosage form for the time and site specific oral drug delivery. Control Release Bioact Mater 1995;22:278-83.

9. Pawar V, Rao G. Development and validation of UV Spectrophotometric method for simultaneous estimation of Montelukast sodium and Bambuterol hydrochloride in bulk and tablet dosage formulation. J Pharm Sci 2008;152-8.

10. Saigal N, Baboota S, Ahuja A, Ali J. Microcrystalline cellulose as a versatile excipient in drug research. $\mathrm{J}$ Young Pharmacist 2009;1:6-12.

11. Battu SK, Repka MA, Majumdar S, Madhusudan RY. Formulation and evaluation of rapidly disintegrating fenoverine tablets: Effect of superdisintegrants. Drug Dev Ind Pharm 2007;33:1225-32.

12. Qureshi J, Amir M, Ahuja A, Baboota S, Ali J. Chronomodulated drug delivery system of salbutamol sulphate for the treatment of nocturnal asthma. Indian J Pharm Sci 2008;70:351-6.

13. Krögel I, Bodmeier R. Floating or pulsatile drug delivery systems based on coated effervescent cores. Int J Pharm 1999;187:175-84.

How to cite this article: Desai M, Jivani RR, Patel LD, Jivani NP, Sonagara B. Development of time controlled chronomodulated tablet with swelling and rupturable layers: Optimization of factors influencing lag-time and drug release. Int $\mathrm{J}$ Pharma Investig 2012;2:208-12.

Source of Support: Nil. Conflict of Interest: None declared. 